\title{
A Study on Experience of Parents and Teachers for the Transition from Elementary to Middle School of Student with Autism Spectrum Disorder
}

\author{
Lee Weon-hee, Shimin, and Kwak Seung-chul \\ Department of Special Education Graduate School, Kong ju National University, KOREA, \\ LeeW.H(2weonhee@hanmail.net), Shimin(shifangrong@hanmail.net), \\ Kwak S.C(sckwak@kongju.ac.kr)
}

\begin{abstract}
The purpose of this study is to provide an efficient transition program for parents and teachers of students with autism spectrum disorders who are in the transition process from elementary to middle school and to suggest the necessity of parent-teacher partnership. To achieve this, data analysis according to the grounded theory was conducted after implementing in-depth interview and focus group interview targeting nine parents and three teachers of students with autism spectrum disorders.

Results of the study are as follows. Firstly, as for parent-teacher experiences, concepts such as difficulties in school life resulting from characteristics of students with autism spectrum disorder, successive transition process of worries, negative view of school life, concerns in the transitions to the middle school, experiences of personal life, strategy for the efficient transition, and preparation process for future were emerged. Secondly, as for the transition programs of elementary and secondary education for students with autism spectrum disorders, there are needs in professional transition counseling, transition education for students, parents, and teachers, liaison to NICE system, systematic diagnosis and placement, and making ITP at the elementary school level. Thirdly, as for parent-teacher partnership in the transition process of students of autism spectrum disorders, three types such as active cooperative relationship, passive cooperative relationship, and non-cooperative relationship were appeared based on the attention and cooperative attitude about transition. Lastly, conditional matrix at personal level, school level, and national level were suggested to demonstrate the core category, that is, the overall explanation of making the efficient transition system by the partnership of parent-teacher.

This study is expected to suggest the direction of developing transition programs and systems for students with disabilities by the systematic understanding of circumstances of transition process based on the grounded theory.
\end{abstract} Theory

Index Terms - Autism Spectrum Disorder, Transition, Grounded

\section{Introduction}

The Family Systems Theory points out that whatever happens to a family member will also have an impact on all the family members, as they are interconnected with each other, and they work as a single group or system. Accordingly, the birth and growth of a child with physical and mental disorder can result in an overall difficulty experienced by family members(Park Hye Seong, 2006; Hong Kyeong Hee, 2003). A child with an autistic disorder, in particular, has an extraordinarily significant impact on the mutual interaction between the handicapped child and other family members due to the unique characteristics of the disorder(Symon, 2001).
According to IDEA(2004), autism is a developmental disorder that has a serious impact on a child's verbal and nonverbal communications, social interaction, and educational achievement. Furthermore, children with autism often show limitations when socializing, in which they are essentially able to perform activities for daily living, participate in effective and proactive activities, respond with linguistic acumen, and interact with other people(Prizant et al., 2008).

Such characteristics of autistic children pose substantial challenges in their lives at home or at school, with particularly significant challenge among the parents with regard to the transitional period of their autistic children(Rous et al., 2007; Winn \& Hay, 2009; Ytterhus et al., 2008). Since students with autism often experience difficulties in adapting to daily changes in schedule or environment, a transition to middle school life without preparation could affect their adaptability towards a new environment due to their inappropriate behavior. Accordingly, it is important to prepare the students for the upcoming changes when setting up a transition plan (Pierangelo \& Giuliani, 2008), and the provision of systematic transition program and cooperation between the parents and teachers are required to help them withstand such transitional period. Even though it is widely understood among the concerned parties that such cooperation is critical in the transition process, it is hard to find studies performed on the cooperation between the parents and teachers during the transition of students with autism to middle school education.

This study aims to publicize the necessity of providing an effective transition program, as well as the importance of cooperation between the parents and teachers, by exploring their experiential domain during the transition of the students with autism to the middle school academic program. For this reason, this researcher concluded that an approach to supporting theories by employing the systematic process proposed by Strauss and Corbin(1998), and the constructionism approach by Charmaz(2006) would be effective in the analysis of the issue. This researcher aims for a successful transition of the students with autism to middle school based on the in-depth data acquired during the interview sessions.

Key issues that reflect the necessity of the study:

First, How is the middle school transition for the students with autism being implemented? 
Second, How is the cooperation between the parents and teachers being implemented over the course of the middle school transition for the students with autism?

\section{Research Method}

\section{A. Research participants}

The research samples and participants have increased over the course of the research process. The selection was performed until all parameters were exhausted, thereby reducing the experiences that matched the research questions into a more sufficient number. A total of 12 participants in the study were composed of 9 parents, who have children with autistic disorder, including $6^{\text {th }}$ graders in elementary schools and $1^{\text {st }}$ graders in middle schools, and 3 teachers of special classes.

\section{B. Collection of data}

The research data was collected through in-depth interviews, which were conducted through questionnaire surveys. The questionnaires consisted mainly of questions on what factors may influence the transition plan and decision of their children, and how their parents and teachers cooperate over the course of the transition. The in-depth interviews with the research participants have been implemented over a period of three months with the interviews being conducted via a Funnel-like approach(Strauss \& Corbin, 1998), in which an open approach is used in the early days of the interview process with increasingly concrete questions being asked over time.

In addition, the IEP of the children, as well as their current educational materials and learning plan, were collected from the participating parents in order to determine the impact of the present learning situations and cognitive levels on their middle school preference. Finally, the data on the percentage of temporary teachers in City D, as well as the learning capability diagnosis, placement schedule, and placement process during the transition to their respective middle schools, were collected by reviewing the newsletters published by the supporting center for special education.

\section{Analysis of collected data}

The analysis of the collected data was performed in accordance with the analysis steps (open coding, axial coding, and selective coding), which were proposed by Strauss and Corbin(1998), and the analysis method by Charmaz(2006) was partially used in the mix.

During the open coding stage, similar concepts were categorized according to their attributes in search of any significant statement that would set the theoretical foundation. Any concept with material significance was extracted by reading the original materials repeatedly and by consulting the line-by-line coding method, while gathering the next stage materials by taking note of the important situations and thoughts of the researcher.

During the axial coding stage, the paradigm methodology was used. This allows the researchers to visualize the connection between different categories. The relationship among the different categories was analyzed by developing and connecting the categories in a systematic manner according to the transition process, as well as the central phenomenon of our interest, while also identifying the categories, subcategories, and concepts according to each item in the paradigm.

During the selective coding stage, this researcher intended to show a general theoretical model on the autistic students' transition from elementary to middle school. The necessity of the transition program was deduced by using the process analysis method in the transition process based on the experience of the parents. Furthermore, the main category was set up and the situation model was created as part of the strategy to identify an effective transition method after studying the cooperation types between the parents and teachers.

\section{Veracity of study}

The reference criteria (credibility, transferability, dependability, and conformability), as proposed by Guba and Lincoln(1985), were used as assessment criteria to enhance feasibility and veracity of the data collection and analysis. This researcher wanted to ensure the veracity of the research by writing an introspection log as part of the strategy to rule out any prejudice in the results deduced from theoretical sampling, member checking, and peer debriefing.

\section{Results}

\section{A. Transition program from elementary to middle school for students with autistic disorder}

The process analysis was performed in order to identify what educational preferences the parents have depending on the situation of the transition process of the autistic students. The analysis showed that the anxiety and fear of the parents, which resulted from the absence of the transition program, are the main phenomena in question. The transition program is composed of the following phases:

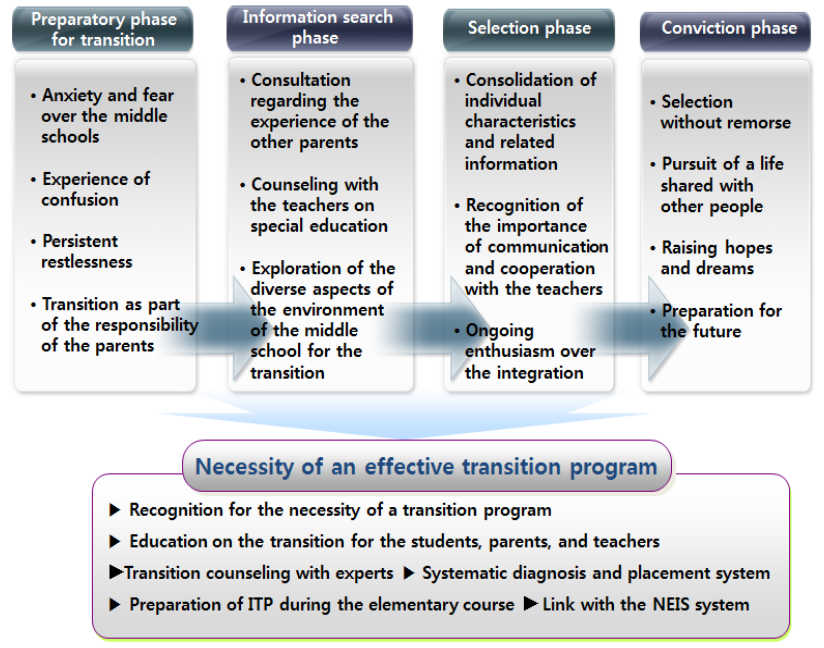

Fig. 1 Perception and experience of the parents of students with autism regarding the transition to middle school. 
B. Cooperative relationship between parents and teachers regarding the transition to middle school

The pattern analysis by Strauss and Corbin (1998) was used to analyze how parents and teachers cooperate during the middle school transition process of the students with autism. The cooperation patterns between the parents and teachers were categorized according to the three key types, which were based on their interest and cooperation on the transition, such as the active cooperative relationship, passive cooperative relationship, and non-cooperative relationship. These patterns were earned by categorizing the results of the interviews with the participants, and indicate that the participants experienced the transition process with particular patterns rather than a specific type.

C. Conditional matrix for an effective transition system through a cooperative relationship between parents and teachers

A conditional matrix was prepared in order to provide a comprehensive overview on the creation of an effective transition system to middle school for autistic students through a cooperative relationship between parents and teachers.

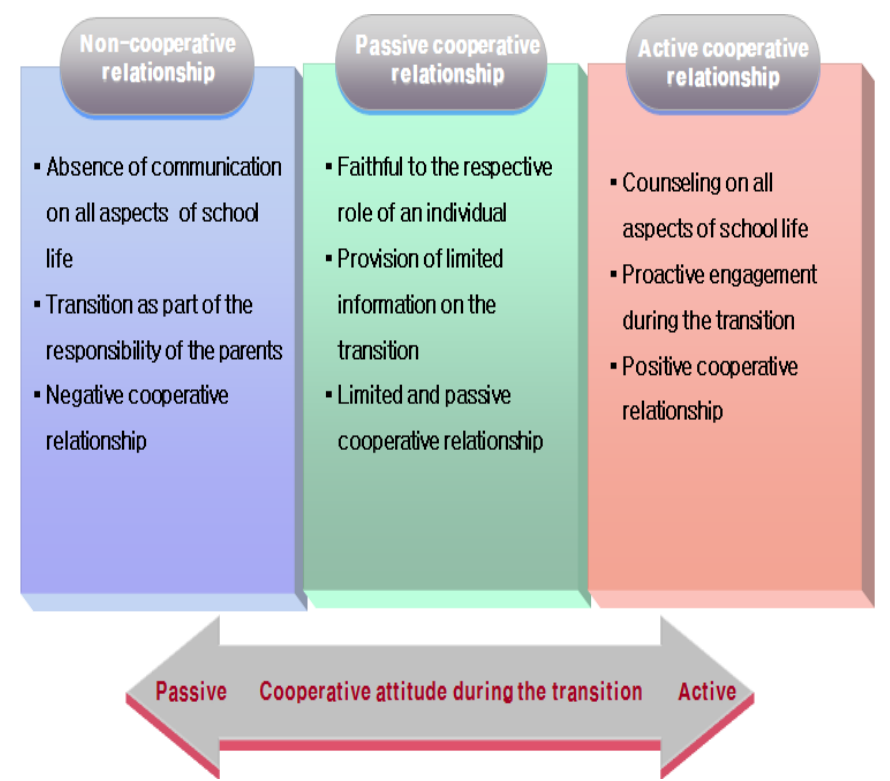

Fig. 2 Types of cooperation between the parents and teachers during the transition process

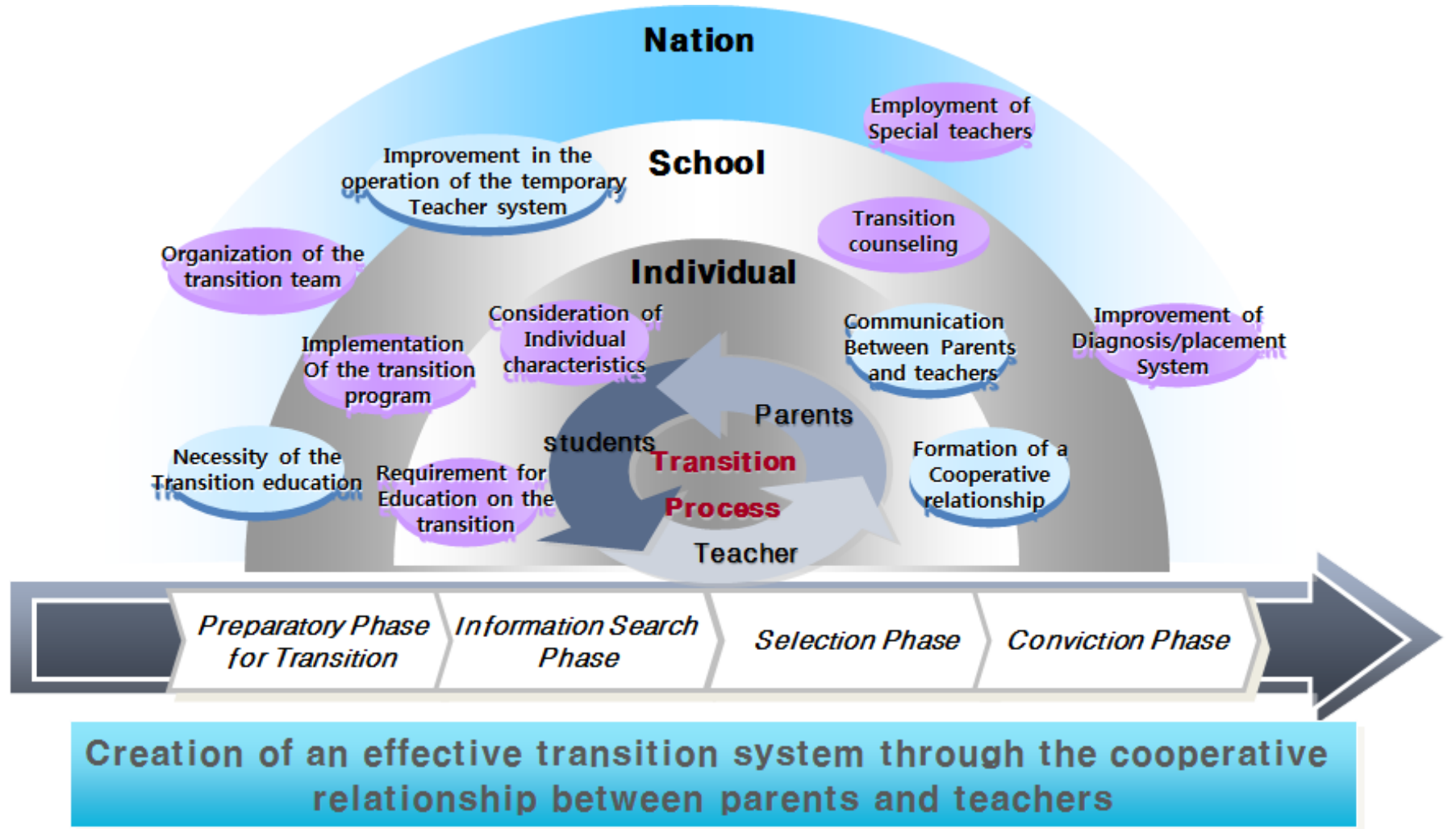

Figure 3: Situation model for an effective middle school transition system through the cooperative relationship between parents and teachers.

\section{Discussion and Recommendation}

\section{A. Discussion}

The study results showed that the parents experienced anxiety over the transition of their children to middle schools.
In fact, the parents started to exchange related information as their children became higher grade students. However, there is no appropriate system that can support the selection of the transition program at a national level. Education regarding the 
transition for the mentally challenged students should be implemented as early as possible through close cooperation and communication between homes and schools. This will require an educational approach suitable for a smooth transition. Accordingly, the transition program tailored for each individual need can minimize the anxiety of the parents during the process. It will also have a positive impact on the handicapped students' adaptability to school life.

The detailed content of the transition program through face-to-face interviews with the parents included the advance technique curriculum, which is a requirement for the middle school, necessity for a dedicated counseling desk, which can provide expert advice, and introduction of a systematic care system, which is tailored for each individual characteristic of the handicapped students. Furthermore, in order to ensure an effective middle school transition for the autistic students, a suite of measures shall be prepared by allowing them to make a transition to an appropriate educational program, distribute school placement system in order to prevent overcrowded classrooms, and prepare the transition by writing ITP (Individual Transition Program) early in their elementary curriculum.

During the course of the transition, the cooperative relationship between the parents and teachers was influenced by factors, such as family attributes, family interactions, and family function, which were suggested by Turnbull and Turnbull(1997). In addition, the knowledge and experience regarding cooperation, non-cooperative educational environment, and communication problems were also influential on the nature of cooperation. In particular, negative instances regarding telephone counseling conducted by temporary teachers have been observed, thereby making it necessary to change the operational method of the temporary teachers at a national level. The creation of a systematic transition support team is also required. The cooperation among parents, teachers, and related specialists in this transition support team would have a positive impact on a family.

\section{B. Limitation of the study and recommendation}

The limitations of the study and associated recommendations are: Firstly, It was discovered in the study that the students with Asperger's syndrome had relatively excellent learning capabilities and self recognition, as compared to those with severe autistic disorder, thereby allowing them to go through a different transition process. Accordingly, a separate study is required with regard to the transition process of the students with Asperger's syndrome by placing them into a different category.
Secondly, This study focused on the individual experiences on the phenomenon discovered during the transition process based on the grounded theory. However, the systematic archival research, in accordance with the grounded theory, had limitations in associating the individual characteristics of the participants with the study results. Therefore, more detailed studies on the individual characteristics of handicapped students, the parents' value system, and the environmental characteristics of the family regarding the middle school transition should be implemented through an individual level analysis.

Thirdly, This study failed to integrate the different perspectives between the parents and teachers. Therefore, it is necessary to explore other factors that may influence their cooperative relationship through the comparison of mutual recognition and experiences, and what kind of impact such cooperation would have on the transition of the handicapped students.

\section{References}

[1] Charmaz. K. (2006). Constructing grounded theory: A practical guide through qualitative analysis. Sage Pubns.

[2] Guba, E., \& Lincoln, Y. (1985). Fourth generation evaluation.London: SAGE Publications.

[3] Hong Kyeong Hee (2003). A Study of the family cohesion and adaptability of mental retardation children and children suffering from autism. Graduate School of Education, Daegu Univesity, Korea

[4] Individuals With Disabilities Education Act (IDEA) of 2004, PL, 10517, 34 C.F.R., Part 300, $\S 300.7$ (b) (1)

[5] Park Hye Seong (2006). Strategies for supporting family of children with autism. Special Education, 5(2), 5-29.

[6] Pierangelo, R., \& Giuliani, G. (2008). Teaching Students With autism Spectrum Disorders. Sage Pubns.

[7] Prizant, B. M., Wetherby, A. M., Rubin E., Laurent, A. M., \& Rydell, P. J. (2008). The SCERTS Model: A Comprehensive Educational Approach for Children with Autism Spectrum Disorders. Michigan: Sheridan Books.

[8] Rous, B., Schroeder, C., Stricklin, S. B., Hains, A., \& Cox, M. (2007). Transition issues and barriers for children with significant disabilities and from culturally and linguistically diverse backgrounds. Lexington: University of Kentucky, Human Development Insititute, National Early Childhood Transition Center.

[9] Strauss, A. \& Corbin, J. (1998). Basics of Qualitative Research: Techniques and Procedures for Developing Grounded Theory. Sage Publication.

[10] Symon, J. B. (2001). Parent education for autism: Issues in providing services at a distance. Journal of Positive Behavior Interventions, 3(30), 106-174.

[11] Turnbull, A. P. \& Turnbull, H. R. (1997). Families, professionals, and exceptionality: A special partnership (3rd ed.). Upper saddle river, NJ: merrill/Prentice Hall.

[12] Winn, S., \& Hay, I. (2009). Transition from school for youth with a disability: Issues and challenges. Disability \& Society, 24(1), 103-115.

[13] Ytterhus, B., Wendelborg, C., \& Lundeby, H. (2008). Managing turning points and transitions in childhood and parenthood? Insights from families with disabled children in Norway. Disability \& Society, 23(6), 625-636. 